\title{
Determinants of the Essential Elements and Vitamins Intake and Status during Pregnancy: A Descriptive Study in Polish Mother and Child Cohort
}

\author{
Agnieszka Jankowska ${ }^{1,+}{ }^{\oplus}$, Mariusz Grzesiak ${ }^{2,3}$, Michał Krekora ${ }^{3,4,+}{ }^{\text {, Jolanta Dominowska }}{ }^{5}$, Joanna Jerzyńska ${ }^{6} \oplus$, \\ Paweł Kałużny ${ }^{7}$, Ewelina Wesołowska ${ }^{7}$, Irena Szadkowska-Stańczyk ${ }^{7}$, Elżbieta Trafalska ${ }^{8}$, Dorota Kaleta ${ }^{8}$, \\ Małgorzata Kowalska ${ }^{9}$, Ewa Jabłońska ${ }^{10}{ }^{\circledR}$, Beata Janasik ${ }^{11}$, Jolanta Gromadzińska ${ }^{11}$, Wojciech Hanke ${ }^{7}{ }^{\circledR}$, \\ Wojciech Wąsowicz ${ }^{11}$, Gemma Calamandrei ${ }^{12}$ (D) and Kinga Polańska ${ }^{1,8, * \mathbb{C}}$
}

1 Department of Environmental and Occupational Health Hazards, Nofer Institute of Occupational Medicine, 91-348 Lodz, Poland; agnieszka.jankowska@imp.lodz.pl

2 Department of Perinatology, Obstetrics and Gynecology, "Polish Mother's Memorial Hospital” Research Institute, 93-338 Lodz, Poland; mariusz.grzesiak@iczmp.edu.pl

3 Department of Gynecology and Obstetrics, Ind Chair of Gynecology and Obstetrics, Medical University of Lodz, 90-419 Lodz, Poland; michal.krekora@iczmp.edu.pl

4 Department of Obstetrics and Gynecology, "Polish Mother's Memorial Hospital” Research Institute, 93-338 Lodz, Poland

check for updates

Citation: Jankowska, A.; Grzesiak, M.; Krekora, M.; Dominowska, J.; Jerzyńska, J.; Kałużny, P.; Wesołowska, E.; Szadkowska-Stańczyk, I.; Trafalska, E.; Kaleta, D.; et al. Determinants of the Essential Elements and Vitamins Intake and Status during Pregnancy: A Descriptive Study in Polish Mother and Child Cohort. Nutrients 2021, 13, 949. https://doi.org/10.3390/ nu13030949

Academic Editors: M. Victoria Arija Val and Katarzyna Socha

Received: 23 December 2020

Accepted: 9 March 2021

Published: 16 March 2021

Publisher's Note: MDPI stays neutral with regard to jurisdictional claims in published maps and institutional affiliations.

Copyright: (c) 2021 by the authors. Licensee MDPI, Basel, Switzerland. This article is an open access article distributed under the terms and conditions of the Creative Commons Attribution (CC BY) license (https:// creativecommons.org/licenses/by/ $4.0 /)$.
5 Department of Teaching Midwifery, Medical University of Lodz, 90-419 Lodz, Poland; jolanta.dominowska@umed.lodz.pl

6 Department of Paediatrics and Allergy, Copernicus Memorial Hospital, Medical University of Lodz, 90-329 Lodz, Poland; joanna.jerzynska@umed.lodz.pl

7 Department of Environmental Epidemiology, Nofer Institute of Occupational Medicine, 91-348 Lodz, Poland; pawel.kaluzny@imp.lodz.pl (P.K.); ewelina.wesolowska@imp.lodz.pl (E.W.); irena.szadkowska-stanczyk@imp.lodz.pl (I.S.-S.); wojciech.hanke@imp.lodz.pl (W.H.)

8 Department of Hygiene and Epidemiology, Medical University of Lodz, 90-752 Lodz, Poland; elzbieta.trafalska@umed.lodz.pl (E.T.); dorota.kaleta@umed.lodz.pl (D.K.)

9 Department of Epidemiology, Medical University of Silesia, 40-752 Katowice, Poland; mkowalska@sum.edu.pl

10 Department of Translational Research, Nofer Institute of Occupational Medicine, 91-348 Lodz, Poland; ewa.jablonska@imp.lodz.pl

11 Department of Biological and Environmental Monitoring, Nofer Institute of Occupational Medicine, 91-348 Lodz, Poland; beata.janasik@imp.lodz.pl (B.J.); jolanta.gromadzinska@imp.lodz.pl (J.G.); wojciech.wasowicz@imp.lodz.pl (W.W.)

12 Centre for Behavioural Sciences and Mental Health, National Institute of Health, I-00161 Rome, Italy; gemma.calamandrei@iss.it

* Correspondence: Kinga.Polanska@imp.lodz.pl; Tel.: +48-42-6314-569

+ These authors contributed equally to this work.

Abstract: The study objective was to identify determinants of essential elements and vitamins intake, and microelements and vitamins concentration in blood among pregnant women from Poland. Based on the data from food frequency questionnaires and information about supplements taken $(n=1252)$, daily supply of six elements (calcium, magnesium, iron, zinc, copper, selenium) and nine vitamins (folate, vitamins A, E, C, B1, B2, B3, B6, B12) was calculated. Zinc, copper, selenium ( $n=340)$, vitamin $\mathrm{A}$ and $\mathrm{E}(n=358)$ concentration was determined in blood collected during pregnancy. Most of the women did not meet the demand for essential elements and vitamins with a diet. About $94 \%$ of the respondents declared supplements use. The women with higher education, indicating leisure-time, physical activity and multiparity had a higher chance of meeting the average demand for the majority of the analyzed nutrients. On the other hand, factors such as BMI $<18.5 \mathrm{~kg} / \mathrm{m}^{2}$, a higher level of stress, and late first medical-care visit were associated with a lower chance of meeting the recommendations. Higher socio-economic status was a determinant of a higher selenium concentration in plasma ( $\beta=3.1 ; 95 \%$ CI: $0.2-5.9$ ), whereas BMI $\geq 25 \mathrm{~kg} / \mathrm{m}^{2}$, and multiparity of a higher copper concentration in plasma ( $\beta=0.2 ; 95 \% \mathrm{CI}$ : $0.03-0.4 ; \beta=0.2 ; 95 \% \mathrm{CI}$ : $0.1-0.4)$. Higher plasma concentration of vitamin $\mathrm{E}$ was noted among women older than 30 years of age comparing to those who were 30 or younger $(\beta=1.5$; 95\%CI: 0.6-2.4). Although more studies are required, especially such based on laboratory 
measures, our results indicate target groups for dietary interventions during pregnancy for children's optimal health and development.

Keywords: essential elements; vitamins; zinc; copper; selenium; diet; plasma; pregnancy; environmental determinants

\section{Introduction}

It is now well recognized that a diet is one of the most important lifestyle related factors that has influence on our health. The diet during pregnancy should be properly balanced and provide all the necessary nutrients. Both excess and deficiency of nutrients, as well as an inadequate supply of essential elements and vitamins, can result in diseases in mother and her offspring or decreased health and developmental potential of a child [1-3]. As an example, deficiencies of certain vitamins and minerals during pregnancy, such as vitamin $\mathrm{E}, \mathrm{C}, \mathrm{B} 6$, calcium $(\mathrm{Ca})$, zinc $(\mathrm{Zn})$, might play a role in pre-eclampsia, whereas iron ( $\mathrm{Fe})$ and $\mathrm{Zn}$ deficiencies are linked to impaired immunity [4]. It is also underlined that $\mathrm{Fe}$, folate and vitamin A deficiencies can be associated with anaemia. Moreover, the role of adequate folates status before conception and at the beginning of pregnancy in the reduction of the risk of neural tube defects is scientifically proven $[4,5]$.

The existing studies point out an association between maternal antenatal diet (defined as: (1) healthy vs. unhealthy based on the consumed food, (2) measured by dietary indices such as Dietary Approaches to Stop Hypertension (DASH) score and Dietary Inflammatory Index (DII) score or (3) evaluated based on individual nutrients intake or status) and birth outcomes, child adiposity, respiratory, cardiometabolic, and neurodevelopmental health [6-13]. This fully complies with the Developmental Origins of Health and Disease hypothesis, underlying that transient environmental exposures during critical periods of development (such as the pre-conceptional, fetal and early infant phases) can alter normal physiology and have a persistent impact on metabolism and gene expression, thereby influencing disease risk in later life and even intergenerationally [14].

While nutritional requirements of the general population can be achieved by an adequate diet, the risk of suboptimal nutrient intake (especially for Fe and folic acid) is common during pregnancy. Therefore, according to the guidelines developed by the World Health Organization (WHO) and The Polish Society of Gynecologists and Obstetricians (PSGO) some supplements might be needed to meet specific recommendations for the whole pregnancy or certain sensitive developmental stages $[4,5,15,16]$. Antenatal supplements that include folic acid and Fe are recommended by WHO in the context of rigorous research [4,5]. PSGO recommends the following folic acid supplementation: $0.4 \mathrm{mg} /$ day before conception and $0.4-0.8 \mathrm{mg} /$ day at the beginning of pregnancy and $0.6-0.8 \mathrm{mg} /$ day after 12 weeks of pregnancy and during lactation. Moreover, assessment of blood count and ferritin concentration at the 1st prenatal visit and then blood count at 15-20, 27-32, 33-37 and 38-39 weeks of gestation is recommended. Fe supplementation before 16 weeks of pregnancy is advised among women with Fe deficiency anemia $(\mathrm{Hb}<11 \mathrm{~g} / \mathrm{dL}$ and low ferritin concentration) and after 16 weeks of pregnancy at a dose of up to $30 \mathrm{mg} /$ day in women without anemia with the ferritin concentration below $60 \mu \mathrm{g} / \mathrm{L}$ [16].

Despite numerous studies confirming importance of a balanced diet during pregnancy, many pregnant women in the world, including those in the developed countries, are still at risk of suboptimal essential elements and vitamins intake [17]. Knowledge on factors that influence dietary choices and, as a consequence, nutritional status during pregnancy is crucial for the assessment of population needs and development of effective public health messages and interventions [18]. Most of the existing research indicates that bettereducated women, those with higher socioeconomic status (SES) and more favorable lifestyle (physically active and nonsmokers) are more inclined to follow dietary recommendations 
and meet the need for essential nutrients [19]. However, some country-specific differences in the subpopulations' adequate minerals and vitamins intake might exist.

The aim of the study was to identify determinants of adequate antenatal intake of essential elements and vitamins from dietary and total (diet and supplements) sources, and determinants of selected microelements and vitamins concentrations in the blood collected during the 1st trimester of pregnancy. The mentioned data is crucial for recognition if pregnant women in Poland meet the demand for the essential nutrients and for identification of vulnerable groups for dietary interventions for children's optimal health and development.

\section{Material and Methods}

\subsection{Study Design and Population}

The study is based on the data from the Polish Mother and Child cohort (REPRO_PL), which was established in 2007 (with the recruitment of women in the 1st trimester of pregnancy over 4 years). REPRO_PL is an ongoing population-based prospective cohort that has been created to investigate the effects of socio-demographic, lifestyle, environmental, and pregnancy-related variables on children's health and development. Detailed information on the REPRO_PL cohort has been published elsewhere [20-22]. The cohort comprises 3 phases covering pregnancy, early childhood (12 and 24 months), and early school age (7 years) periods. The present analysis includes data that has been collected during pregnancy.

In total, 1764 pregnant women were included into the REPRO_PL cohort [20]. Information regarding their diet and medications/supplements use was provided by 1508 women $(86 \%)$ by completing questionnaires during the 1st and/or 2nd trimester of pregnancy. Of this group, 1306 women filled in the food frequency questionnaire (FFQ). Moreover, 202 women completed the $24 \mathrm{~h}$ Dietary Recall Questionnaire (24HR) and they were excluded from the current analysis. The final sample was restricted to 1252 women (96\%) after exclusion of those with missing $(n=40)$ or inaccurate data (i.e., implausible energy intakes $(<500$ or $>3500 \mathrm{kcal} /$ day); $n=5$ ) or women following special diets (i.e., vegetarian or vegan; $n=9)[23,24]$. Assessment of microelements and vitamins concentration in blood plasma, which was collected during the 1st trimester of pregnancy, was performed on a subsample of the population (microelements: $n=340$; vitamins: $n=358$ ).

The study was approved by the Ethical Committee of the Nofer Institute of Occupational Medicine, Lodz, Poland (Decision No. 7/2007), and written consent was obtained from all the study subjects.

\subsection{Assessment of Essential Elements and Vitamins Intake Based on Questionnaire Data}

A detailed description of dietary data collection procedure and the FFQ has been published previously [25-28]. Briefly, the women, assisted by trained personnel, reported their consumption for a list of foods on a frequency scale with the following response categories: (a) never, (b) less than once per month, (c) 1-3 times per month, (d) 1-3 times per week (e) 4-6 times per week, and (f) every day. Based on the frequency of food products consumption and the size of an average portion, the content of 6 essential elements (calcium $(\mathrm{Ca})$, magnesium $(\mathrm{Mg})$, iron $(\mathrm{Fe})$, zinc $(\mathrm{Zn})$, copper $(\mathrm{Cu})$ and selenium $(\mathrm{Se}))$ and 9 vitamins (folate, vitamin A, E, C, thiamin (B1), riboflavin (B2), niacin (B3), pyridoxine (B6), cobalamin (B12)) in the consumed diet was calculated using the Polish Food Composition Tables [29]. These values were related to dietary standards, which allowed for the calculation of the percent of implementation of dietary recommendations (estimated average requirement (EAR) for the analyzed essential elements and vitamins is presented in Supplementary Materials: Table S1) [30].

During the 1st and 2nd prenatal visits, scheduled within the study, the women were interviewed by a gynecologist or midwife about the use of medications and supplements [20]. They provided the name, dose and period of their intake. Based on this information, the intake of essential elements and vitamins with supplements was calculated and included in the analyses. 


\subsection{Determination of Microelements and Vitamins in Biological Samples}

Blood samples taken from the women during the 1st trimester of pregnancy were centrifuged and plasma samples were collected, and then stored until the analyses. Concentrations of the selected microelements and vitamins were measured in the plasma samples using the methods that have been described in detail elsewhere [31,32]. Briefly, the flame atomic absorption spectrometry (FAAS) method was used for measurement of $\mathrm{Zn}$ and $\mathrm{Cu}[33]$ and the graphite furnace atomic absorption spectrometry (GFAAS) for Se concentrations in biological samples [34,35]. The use of the HPLC system integrated with the UV-VIS 190-800 nm detector allowed for the determination of vitamins A and E concentration in plasma [36].

\subsection{Covariates}

All the variables considered in the study were described in detail previously [27]. Briefly, the following socio-demographic covariates were assessed: maternal age, educational level, marital status, occupational activity between the 8th-12th weeks of pregnancy and socio-economic status (SES) (based on a subjective assessment as described by Polanska et al. 2017) [31]. In addition, two environmental factors, namely place of residence (based on the number of inhabitants) and seasonality (as the month of filling FFQ), were investigated. We also considered five variables related to lifestyle/health behaviour: maternal smoking status (with $10 \mathrm{ng} / \mathrm{mL}$ as a cut-off point for cotinine level in saliva being an indicator of active smoking as described by Wesolowska et al. 2019 and Stragierowicz et al. 2013) [27,37], alcohol consumption (yes and no), leisure-time physical activity (LTPA) (yes and no), the level of stress (based on the perceived stress scale (PSS) as described by Wesolowska et al. 2019) during pregnancy [27] and pre-pregnancy BMI $\left(\mathrm{kg} / \mathrm{m}^{2}\right)$. Moreover, the following pregnancy-related variables were assessed: parity, pregnancy-related adverse symptoms and complications and week of pregnancy of the 1st medical-care visit (based on medical records taking into account the date of the 1st medical-care visit and the date of the last menstrual period). Finally, the sex of a child was also considered.

\subsection{Statistical Analysis}

Data regarding characteristics of the population, intake of essential elements and vitamins as well as microelements and vitamins concentrations in the blood samples are presented as numbers and percentages for categorical variables or means and standard deviations (SD) for continuous variables.

The level of consumption of the studied essential elements and vitamins were considered as a binary variable (coded as $0=$ below the recommended level and $1=$ equal or exceeding the recommended level). Intake from dietary sources and total intake from dietary sources and supplementation were considered as separate outcome variables.

First, crude odds ratios (ORs) for attaining the recommended level of every essential element and vitamin in groups of mothers defined by each categorical determinant of interest was calculated by simple logistic regression models with one explanatory variable. Then, mutually adjusted ORs were calculated with a multiple logistic regression models. The outcome variable was considered for multiple logistic regression modelling if manageable number of subjects of each category were present in the study population (thus, folate and Fe from dietary sources were not presented for multivariable modeling). Each multivariable model comprised the following explanatory variables: maternal age ( $\leq 30$ years (ref.), $>30$ years); maternal education ( $\leq 12$ years of education (ref.), $>12$ years); occupational activity (no (ref.), yes); SES (low/middle (ref.), high); pre-pregnancy BMI $\left(<18.5 \mathrm{~kg} / \mathrm{m}^{2}, 18.5 \mathrm{~kg} / \mathrm{m}^{2}-24.9 \mathrm{~kg} / \mathrm{m}^{2}\right.$ (ref.), $\geq 25$ ); LTPA (no (ref.), yes); PSS ( $<17$ points (ref.), $\geq 17$ points); place of residence ( $<100,000$ inhabitants, $\geq 100,000$ inhabitants (ref.)); a season of the year when the questionnaire was filled in (May-October, November-April (ref.)); parity ( 0 (ref.), $\geq 1$ child); the 1 st medical-care visit during pregnancy ( $\leq 6$ weeks (ref.), $>6$ weeks). Initially, more variables were considered as potential determinants: (marital status (married (ref.), unmarried); smoking (cotinine level in saliva $<10 \mathrm{ng} / \mathrm{mL}$ (ref.), 
$\geq 10 \mathrm{ng} / \mathrm{mL}$ ); alcohol consumption (no (ref.), yes); adverse symptoms and complications (no (ref.), yes); the sex of a child (male (ref.), female) but they were not included in the multiple logistic regression modelling. Either they consistently had no statistically significant crude effects, or confidence limits for multivariable ORs of these variables were not reliably estimable due to similarity to the outcome variables. The OR with $95 \%$ confidence intervals $(95 \% \mathrm{CI})$, were presented as forest plots. Numerical values of OR and $95 \% \mathrm{CI}$ from the univariable and multivariable models were also tabulated in Supplementary Materials.

To assess determinants of plasma concentrations of $\mathrm{Zn}, \mathrm{Cu}$, Se, vitamins $\mathrm{A}$ and $\mathrm{E}$, these outcome variables were modeled using the ordinary linear regression with the same set of explanatory variables as the stated above. Regression coefficients $\beta$ with $95 \% \mathrm{CI}$ from the univariable and multivariable analyses were presented in the tables. Multivariable models for plasma concentrations omitted the following variables: marital status, adverse pregnancy symptoms and complications, and sex of a child, because none of the coefficients from the univariable analyses were below 0.1 significance level.

The significance level of $p=0.05$ was assumed in all the statistical procedures. The $\mathrm{R}$ software for statistical computing (version 3.5.1) was applied for statistical modeling and data processing; the R package forestplot (https: / /CRAN.R-project.org/package= forestplot; accessed on 20 December 2020) was used for plotting regression results [38].

\section{Results}

\subsection{Characteristics of the Study Population}

Table S2 summarizes socio-demographic, lifestyle, environmental and pregnancyrelated sample characteristics. The majority of women were 30 years of age or younger $(64 \%)$, married $(81 \%)$, declared a university degree $(69 \%)$. One in four women assessed their SES as high (24\%). Among the examined women, $55 \%$ were professionally active between the 8 th and 12th weeks of pregnancy. About $18 \%$ of the respondents were classified as overweight or obese before their current pregnancy and $11 \%$ as active smokers during pregnancy. Moreover, $7 \%$ of the women indicated alcohol consumption and $69 \%$ reported LTPA during pregnancy. The 1st medical-care visit at the 6th week of pregnancy or earlier was reported by almost two-thirds of the women (59\%) and about $4 \%$ of them noticed adverse pregnancy symptoms or complications up to the 2 nd trimester of pregnancy. More than half of the women were in their first pregnancy $(51 \%)$.

\subsection{Factors Associated with Adequate Intake of Essential Elements and Vitamins during Pregnancy}

Table S3 shows the percentage of pregnant women using dietary supplements and percentages of selected essential elements and vitamins from the supplements. A total of $94 \%$ of the respondents declared the use of supplements during pregnancy. The highest levels of supplementation were related to folate (100\%) and vitamin B6 (50\%). Essential elements supplemented to the lowest extent were $\mathrm{Cu}(7 \%)$ and vitamins $\mathrm{B} 1$ and $\mathrm{B} 2(2 \%)$.

Details on the intake of essential elements and vitamins from a diet and total consumption (from a diet and supplementation) are presented in Table S4 and Figure 1. The vast majority of the women (which in the current study represent more favourable sociodemographic status: university degree and high SES, marital status) did not meet the demand (referred to EAR) for most essential elements and vitamins along with a diet. As an example, inadequate intakes were noted for more than $80 \%$ of the study population for $\mathrm{Mg}$, Fe and folate with the substantial improvement achieved with the supplementation of folate ( $93 \%$ of the population meet EAR from total consumption). Only for $\mathrm{Cu}$, vitamins A, B2, B3, and B12, more than 70\% of the women met the EAR with the consumed diet. 

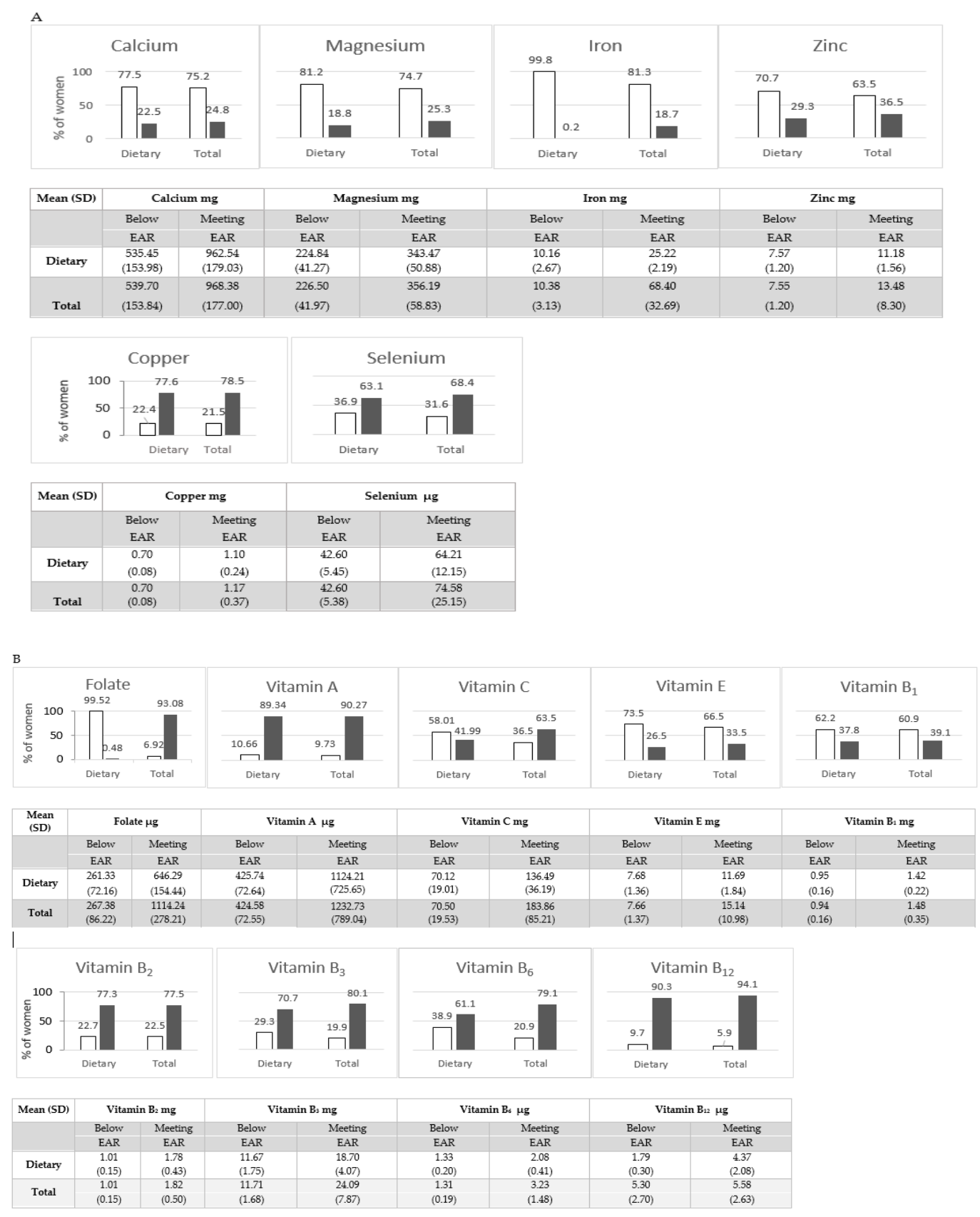

Figure 1. Intake of essential elements (A) and vitamins (B) from diet and total intake (from diet and supplementation) according to daily intake category: $\square$ Below EAR, $\square$ Meeting EAR. Note: EAR (Estimated Average Requirement) for essential elements and vitamins during pregnancy are presented in Supplementary Materials (Table S1).

Results of the univariable models for determinants of adequate intake of selected essential elements and vitamins from dietary and total (dietary and supplements) sources are presented in Tables S5 and S6. The data from relevant multivariable models are presented in Tables S7 and S8 as well as in a form of a forest plot (Figure 2). The women with a university degree had a higher chance of achieving adequate intake of essential elements and vitamins from dietary sources (Ca: $\mathrm{OR}=1.5 ; 95 \% \mathrm{CI}: 1.1-2.1 ; \mathrm{Mg}$ : $\mathrm{OR}=1.6$; 95\%CI: 1.1-2.3; Zn: OR = 1.4; 95\%CI: 1.1-1.9; Se: OR = 1.5; 95\%CI: 1.1-2.0; vitamin B1: $\mathrm{OR}=1.4 ; 95 \% \mathrm{CI}: 1.0-1.8$; vitamin $\mathrm{B} 3: \mathrm{OR}=1.4 ; 95 \% \mathrm{CI}: 1.0-1.8)$ ) comparing to those with a lower educational level (Figure 2; Table S7). Moreover, a higher educational level was a determinant of an adequate status for folate (OR $=2.8 ; 95 \% \mathrm{CI}$ : 1.7-4.6) (Figure 2 and Table S8). The older women had a higher (OR = 1.4; 95\%CI: 1.1-1.9) and those working 
during pregnancy a lower ( $\mathrm{OR}=0.7 ; 95 \% \mathrm{CI}$ : $0.5-0.9)$ chance of adequate Se intake with dietary sources comparing to the younger and unemployed ones (Figure 2 and Table S7). The women declaring high SES achieved EAR with dietary sources for vitamin C $(\mathrm{OR}=1.5$; 95\%CI: 1.2-2.0) more frequently as compared to the women with lower SES (Figure 2 and Table S7). The women classified as underweight before pregnancy had a lower chance of achieving vitamin B2 (OR $=0.5 ; 95 \% \mathrm{CI}$ : 0.3-0.9) and B12 (OR $=0.4 ; 95 \% \mathrm{CI}: 0.2-0.7)$ requirements with a diet, and $\mathrm{Zn}(\mathrm{OR}=0.6$; $95 \% \mathrm{CI}$ : $0.4-1.0)$ with total (dietary and supplements) sources (Figure 2, Tables S7 and S8) compared to those within the recommended BMI category. Recreational physical activity during pregnancy was a strong determinant of adequate essential elements and vitamins intake $(p<0.05)$ (Figure 2 and Tables S7 and S8). On the other hand, a higher number of points from PSS (indicating a higher level of stress) was associated with a lower chance of achieving EAR for some essential elements $(\mathrm{Cu}$, Se) and vitamins (C, B3, B6, B12) $(p \leq 0.05))$ (Figure 2 and Tables S7 and S8). The place of residence was not a significant determinant of an adequate essential elements and vitamin status. The multiparous mothers had a higher chance to meet EAR recommendations for $\mathrm{Cu}(\mathrm{OR}=1.5 ; 95 \% \mathrm{CI}: 1.1-2.1)$, Se $(\mathrm{OR}=1.5 ; 95 \% \mathrm{CI}: 1.2-2.0)$, vitamin A $(\mathrm{OR}=1.7 ; 95 \% \mathrm{CI}$ : 1.1-2.6) and vitamin B6 (OR = 1.4; 95\%CI: 1.0-2.0—for total: dietary and supplement sources) as compared to the nulliparous women (Figure 2 and Tables S7 and S8). Finally, a late 1st medical-care visit was associated with a lower chance of achieving EAR from total (dietary and supplements) sources for Se (OR $=0.7 ; 95 \% \mathrm{CI}$ : $0.6-1.0)$, folates $(\mathrm{OR}=0.5$; 95\%CI: 0.3-0.8) and vitamin A (OR = 0.7; 95\%CI: 0.4-1.0) (Figure 2 and Table S8).

A

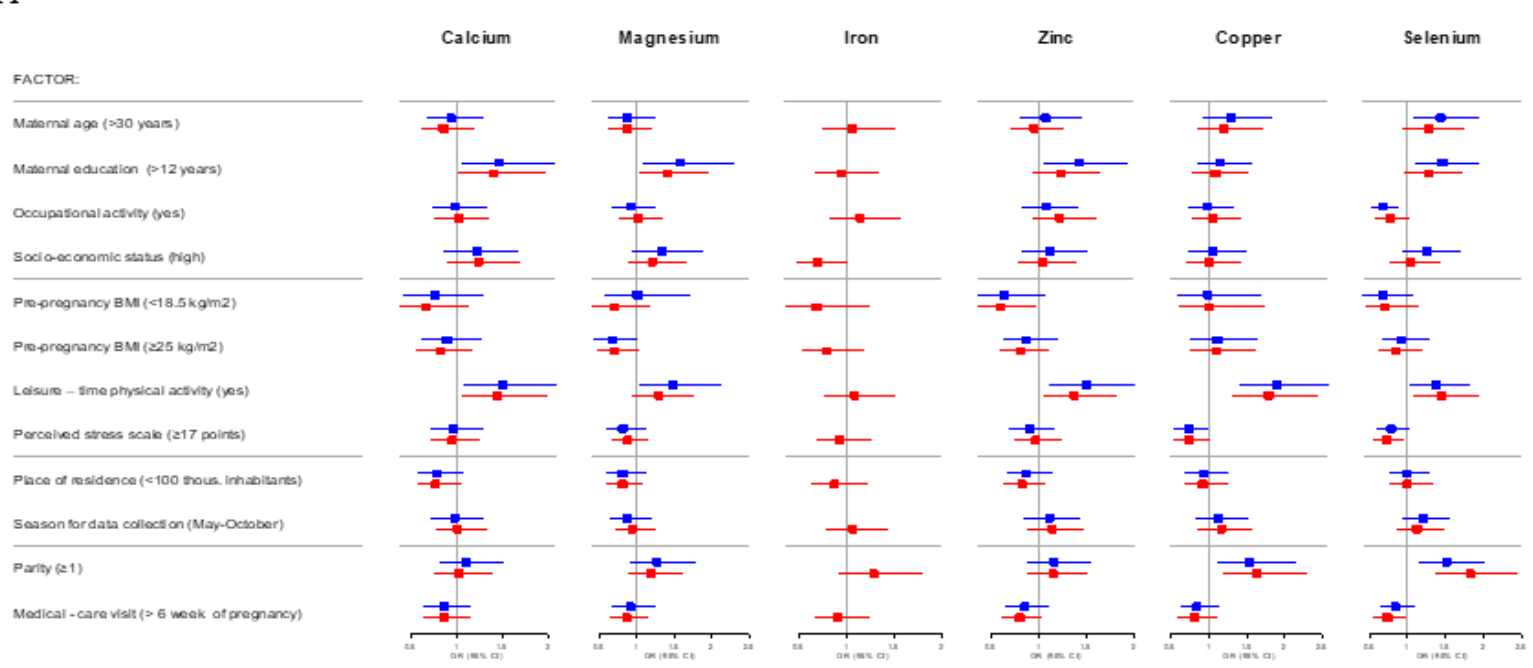

B

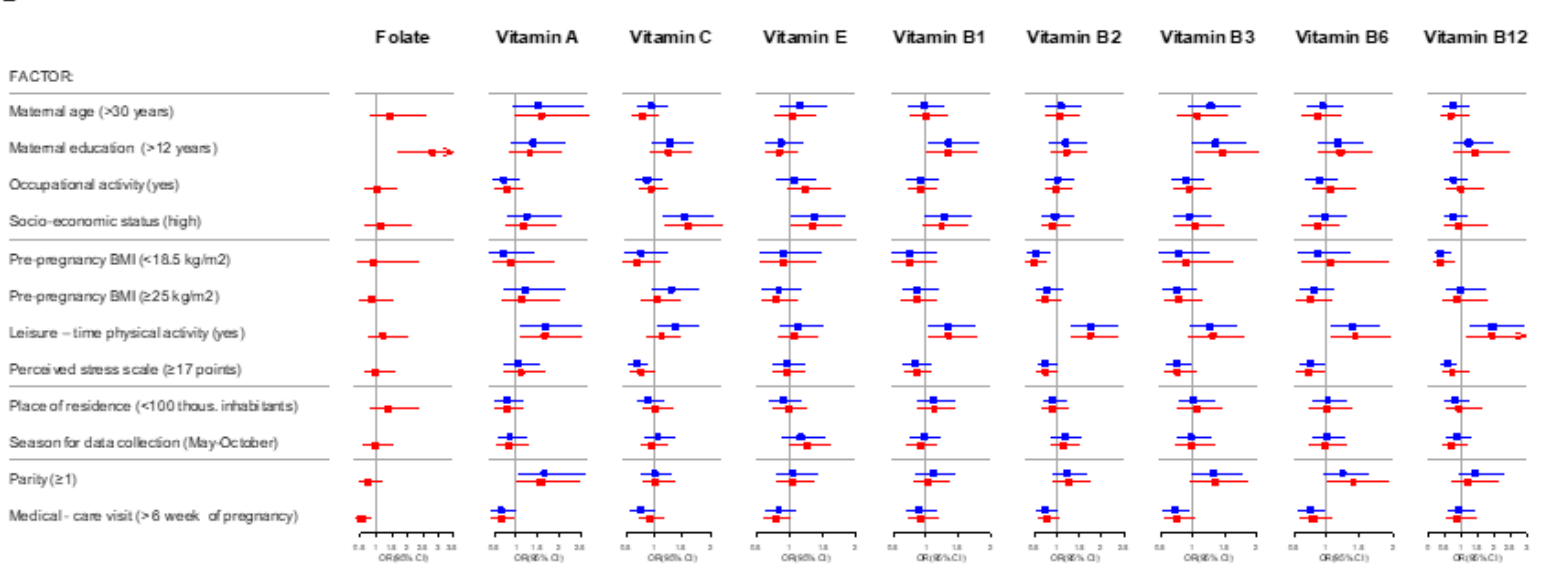

Figure 2. Adjusted effects of the explanatory factors for the adequacy of intake of selected essential elements (A) and vitamins (B) from dietary (blue) and total (dietary and supplementation) (red) sources, estimated by multivariable logistic 
regression models. For iron intake from dietary sources multivariable modelling was not feasible, because only 2 mothers attained recommended level. For folate intake from dietary sources multivariable modelling was not feasible, because only 6 mothers attained the recommended level. Reference groups: maternal age $\leq 30$ years; maternal education $\leq 12$ years; occupational activity between the 8th-12th weeks of pregnancy-no; SES—low /medium; pre-pregnancy BMI $\left(\mathrm{kg} / \mathrm{m}^{2}\right)$ 18.5-24.99; LTPA—no; PSS < 17 points; place of residence (thousands of inhabitants) $\geq 100$; season for data collectionNovember-April; parity-0; week of pregnancy of the 1 st medical-care visit $\leq 6$.

\subsection{Factors Associated with Microelements and Vitamins Concentration in Blood Collected during Pregnancy}

The mean $( \pm S D)$ microelements and vitamins concentration in blood (plasma) collected during the 1st trimester of pregnancy is presented in Table S9. Table S10 (the univariable linear regression model) and Table 1 (the multivariable linear regression model) show determinants of micronutrients and vitamins concentration in plasma. Based on the multivariable linear regression model, higher SES was a significant determinant of a higher Se concentration ( $\beta=3.1 ; 95 \% \mathrm{CI}: 0.2-5.9)$ and BMI $\geq 25 \mathrm{~kg} / \mathrm{m}^{2}$ as well as multiparity of a higher $\mathrm{Cu}$ concentration ( $\beta=0.2 ; 95 \% \mathrm{CI}$ : $0.03-0.4$ and $\beta=0.2 ; 95 \% \mathrm{CI}$ : $0.1-0.4$, respectively). Higher concentration of vitamin $\mathrm{E}$ was noted among the women older than 30 compared to those who were 30 or younger $(\beta=1.5$; $95 \% \mathrm{CI}$ : $0.6-2.4)$.

Table 1. Adjusted effects of the explanatory factors on microelements and vitamins concentrations in blood plasma samples collected during the 1st trimester of pregnancy estimated by multivariable linear regression models.

\begin{tabular}{|c|c|c|c|c|c|}
\hline Determinant & $\begin{array}{c}\text { Zinc } \\
(\mathrm{mg} / \mathrm{L})\end{array}$ & $\begin{array}{l}\text { Copper } \\
(\mathrm{mg} / \mathrm{L})\end{array}$ & $\begin{array}{l}\text { Selenium } \\
(\mu \mathrm{g} / \mathrm{L})\end{array}$ & $\begin{array}{c}\text { Vitamin A } \\
(\mathrm{mg} / \mathrm{L})\end{array}$ & $\begin{array}{l}\text { Vitamin E } \\
(\mathrm{mg} / \mathrm{L})\end{array}$ \\
\hline \multicolumn{6}{|c|}{$\beta(95 \% \mathrm{CI})$} \\
\hline \multicolumn{6}{|l|}{ Maternal age } \\
\hline$>30$ & $0.04(-0.03,0.10)$ & $-0.08(-0.22,0.07)$ & $2.56(-0.15,5.27)$ & $0.01(-0.06,0.08)$ & $1.51(0.62,2.39) *$ \\
\hline \multicolumn{6}{|c|}{ Maternal education (years) } \\
\hline$>12$ & $-0.05(-0.12,0.02)$ & $0.04(-0.11,0.19)$ & $-0.98(-3.76,1.80)$ & $0.01(-0.06,0.09)$ & $-0.23(-1.14,0.68)$ \\
\hline \multicolumn{6}{|c|}{ Occupational activity between the 8th and 12th week of pregnancy } \\
\hline Yes & $-0.06(-0.12,0.01)$ & $-0.09(-0.23,0.04)$ & $0.22(-2.30,2.73)$ & $0.09(-0.03,0.16)$ & $-0.32(-1.12,0.47)$ \\
\hline \multicolumn{6}{|c|}{ Socio-economic status (SES) } \\
\hline High & $0.03(-0.04,0.11)$ & $-0.04(-0.19,0.12)$ & $3.07(0.21,5.94)^{\wedge}$ & $0.03(-0.04,0.09)$ & $-0.35(-1.22,0.52)$ \\
\hline \multicolumn{6}{|c|}{ Pre-pregnancy BMI $\left(\mathrm{kg} / \mathrm{m}^{2}\right)$} \\
\hline$<18.5$ & $0.01(-0.10,0.12)$ & $-0.11(-0.35,0.14)$ & $-0.89(-5.46,3.68)$ & $-0.08(-0.21,0.05)$ & $-1.41(-3.00,0.18)$ \\
\hline$\geq 25$ & $0.07(-0.00,0.15)$ & $0.19(0.03,0.35)$ & $1.98(-1.04,5.00)$ & $0.05(-0.03,0.13)$ & $-0.28(-1.25,0.70)$ \\
\hline \multicolumn{6}{|l|}{ Cotinine level } \\
\hline $\begin{array}{l}\geq \geq 10 \mathrm{ng} / \mathrm{mL} \\
\text { Alcohol consump }\end{array}$ & $0.05(-0.05,0.15)$ & $0.05(-0.17,0.27)$ & $-2.29(-6.35,1.77)$ & $0.03(-0.08,0.13)$ & $0.49(-0.82,1.80)$ \\
\hline Yes & $0.01(-0.09,0.11)$ & $-0.02(-0.24,0.20)$ & $-2.30(-6.33,1.73)$ & $0.08(-0.03,0.19)$ & $1.28(-0.10,2.66)$ \\
\hline \multicolumn{6}{|c|}{ Leisure-time physical activity (LTPA) } \\
\hline Yes & $0.05(-0.01,0.12)$ & $0.04(-0.10,0.18)$ & $2.45(-0.14,5.04)$ & $0.03(-0.03,0.10)$ & $-0.24(-1.06,0.59)$ \\
\hline \multicolumn{6}{|c|}{ Perceived Stress Scale (range: $0-38$ points)(PSS) } \\
\hline$\geq 17$ points & $0.07(0.00,0.13)$ & $-0.05(-0.18,0.08)$ & $-0.40(-2.85,2.05)$ & $-0.03(-0.09,0.03)$ & $0.22(-0.56,0.99)$ \\
\hline \multicolumn{6}{|c|}{ Place of residence (thousands of inhabitants) } \\
\hline$<100$ & $-0.06(-0.13,0.01)$ & $0.09(-0.06,0.24)$ & $0.29(-2.51,3.09)$ & $-0.09(-0.16,0.02)$ & $0.21(-0.63,1.06)$ \\
\hline \multicolumn{6}{|c|}{ Season for data collection } \\
\hline May-October & $0.01(-0.06,0.07)$ & $0.04(-0.09,0.17)$ & $2.03(-0.39,4.46)$ & $-0.04(-0.10,0.02)$ & $0.70(-0.06,1.46)$ \\
\hline \multicolumn{6}{|l|}{ Parity } \\
\hline$\geq 1$ & $0.01(-0.05,0.08)$ & $0.21(0.07,0.36) *$ & $0.18(-2.46,2.82)$ & $-0.00(-0.07,0.06)$ & $-0.61(-1.45,0.24)$ \\
\hline \multicolumn{6}{|c|}{ Week of pregnancy of the 1st medical-care visit } \\
\hline$>6$ & $0.02(-0.05,0.08)$ & $-0.01(-0.15,0.12)$ & $0.58(-1.92,3.09)$ & $0.02(-0.05,0.08)$ & $-0.38(-1.18,0.41)$ \\
\hline
\end{tabular}

Reference groups: maternal age $\leq 30$ years; maternal education $\leq 12$ years; occupational activity between the 8th-12th week of pregnancy-no; SES-low /medium; pre-pregnancy BMI $\left(\mathrm{kg} / \mathrm{m}^{2}\right)$-18.5-24.99; cotinine level < $10 \mathrm{ng} / \mathrm{mL}$; alcohol consumption-no; LTPA-no; PSS $<17$ points; place of residence (thousands of inhabitants) $\geq 100$; season-November-April; parity-0; week of pregnancy of the 1st medical-care visit $\leq 6 .{ }^{\wedge} p<0.05 ;{ }^{*} p<0.01$, Each coefficient $\beta$ represents expected increase/decrease in microelement or vitamin concentration, associated with the determinant, relative to the reference group, adjusted for all other determinants listed in the table.

\section{Discussion}

The presented study indicates that the vast majority of women in Poland did not meet the demand for the most essential elements and vitamins with the food they consumed. Moreover, despite widespread use of supplements in the analyzed population, still in 
the case of some crucial minerals and vitamins the recommendations were not met. The assessments based on the questionnaire data show that a higher chance of meeting the average demand for majority of the analyzed nutrients was observed among the women with a higher educational level, declaring LTPA during pregnancy and multiparity, whereas factors such as: being underweight, experiencing a higher level of stress or late the 1st medical-care visit were associated with a lower chance of meeting the recommendations. Moreover, the analysis based on microelements and vitamins concentration in blood collected during the 1st trimester of pregnancy indicates a higher SES as a determinant of a higher Se concentration, BMI $\geq 25 \mathrm{~kg} / \mathrm{m}^{2}$ as well as multiparity as a determinant of a higher $\mathrm{Cu}$ concentration and older age ( $>30$ years) as a determinant of a higher vitamin E concentration. We believe that our results have important implications for health professionals and public health authorities as well as for future research. They might help support adequate dietary practices before and during pregnancy for children's optimal health and development.

According to the current recommendations, pregnant women should consume a healthy, balanced diet consistent with guidelines on healthy eating to guarantee the right amount of energy and nutrients, as well as an adequate supply of vitamins and minerals $[4,5,39]$. What is important is that, in line with the statements of WHO and majority of medical associations, a routine usage of dietary supplements by all pregnant women is not recommended $[4,5,15,16]$. Moreover, it needs to be underlined that some disparities exist in the recommended level of nutrients intake across the countries, which can result from scientific evidence available when the recommendations were developed or criteria selected for the development of specific guidelines [17].

In our study, about $94 \%$ of the pregnant women declared supplements use. The estimates from the developed countries, including USA and countries in Europe, indicate that prenatal dietary supplementation has been used by $70-98 \%$ of the women [40-42]. Similarly to the data from other studies, our analysis confirms that folic acid is the most commonly taken supplement. The EuroPrevall cohort study conducted in nine European countries shows the uptake of folic acid in Poland by $80 \%$ of women (the highest uptake was observed in Spain and the UK: $98 \%$ and $88 \%$, respectively, and the lowest in Lithuania: $56 \%$ ) [40]. Fe supplementation is recommended in Poland under specific circumstances (as it was described previously) and our data indicate that it is taken by $24 \%$ of the pregnant women. These percentages are lower compared to other data from Poland, where $35 \%$ women declared Fe supplementation [43]. It is worth mentioning that the slight differences between studies may be partially a result of different gestational ages within study populations.

As it was underlined previously, a healthy and balanced diet should guarantee all necessary nutrients to a developing fetus. However, our assessments and the data from other studies (including those conducted in Poland) indicate that for some recommended values for minerals and vitamins, with important roles during pregnancy, nutritional adequacy has not been achieved [44-46]. This indicates that more attention should be paid to a better knowledge on the principles of a healthier diet in accordance with the existing recommendations. Polish guidelines, which are in line with that developed by $\mathrm{WHO}$, advise eating meals regularly and composing them using products from all groups (vegetables and fruit; wholegrains; dairy; meat; fish; eggs; vegetable oils and legumes). Salty snacks, dairy sweets drinks and deserts that have typically been characterized as these with poor nutritional value, containing mainly fat and sugars should be limited. Moreover, processed food should be avoided [39,47,48]. Our analysis, similarly to other studies in this field, shows that supplements can increase but not always ensure the recommended minerals and vitamins intake [41,44]. It needs to be underlined that some nutrients were received cumulatively and in large amounts from different supplements, whereas at the same time some relevant supplementation was missing. Bioavailability of microelements in different supplementation products was not considered, and remains a possible source of uncertainty in our estimates of total intakes including supplementation. Nevertheless, 
considering all existing data, dieticians, nutritionists, physicians and other healthcare providers should be able to offer accurate and evidence-based advice on supplement use in pregnancy. Routine supplementation may not be necessary for all women, and in some cases it may even carry a health risk, thus, laboratory data could be required for appropriate supplementation planning and management [42,49].

There are several factors, both environmental and lifestyle-related, that can determine dietary choices, supplement use as well as essential elements and vitamin levels in the body [44,50-60]. A lower educational level and SES of the family may be a risk factor for an unhealthy lifestyle, including an improper diet, obesity or smoking [59,61]. Moreover, women with a lower educational level and SES usually schedule their 1st medical-care visit later in pregnancy and meet a gynecologist or midwife less often, which decreases their chances for dietary assessments and modifications as well as adequate supplement use [7]. This has been also observed in our current study (and similarly in a previously published analysis that was based on dietary patterns) where the women with higher education and indicating recreational physical activity represented better dietary choices and, as a consequence, had a higher chance of meeting the average demand for the majority of the analyzed nutrients [27]. On the other hand, the late 1st medical-care visit was associated with a lower chance of meeting the recommendations. It needs to be underlined that in this study, we have categorized the 1st prenatal visit as before or equal 6 weeks of gestation and after 6 weeks of gestation. Setting the cut-off point for an early prenatal check-up at week 6 of gestation seems to be adequate in terms of doing it as early as possible, but it may be biased as some of the women (especially these with irregular menstrual period) in that week may be unaware of their state of pregnancy. Taking this into account, the week of pregnancy of the 1st medical-care visit has been additionally considered as a continuous variable in the analyses (data not shown). The results were similar to those obtained in the previous models - later the 1st medical-care visit translated into a lower chance of meeting the average demand for majority of the analyzed nutrients.

What is interesting is that in the present assessments the multiparous women had a higher chance of meeting the average demand for some of the nutrients. To date, findings on how parity can impact nutritional choices are not fully conclusive [19,62-65]. It is possible that parity can be a marker for socio-demographic factors or that the influence of parity on dietary choices may depend on a wider context (e.g., support allocated to the women in their first pregnancy and those who already have children) [19]. Moreover, mothers who already have children may pay more attention to the quality of meals prepared for the whole family and, therefore, they may choose food with an increased nutritional value.

A detailed discussion of the micronutrient and vitamin concentrations in the biological samples observed in our population has been published elsewhere $[31,32,66]$. It needs to be underlined that micronutrient and vitamins concentrations can vary depending on the pregnancy period. Moreover, they can also vary worldwide from low to even toxic concentrations [67-71]. In our population, higher SES was a determinant of a higher Se concentration in blood, which is in agreement with the questionnaire data where a higher educational level and SES were related to higher Se intake with a diet. Similarly, a higher $\mathrm{Cu}$ concentration in the blood and higher intake with a diet and total (diet and supplements) was observed among the multiparous women. We also observed a higher $\mathrm{Cu}$ concentration among overweight women compared to those within the recommended weight category. This observation is consistent with other studies showing a generally positive association between serum $\mathrm{Cu}$ level and obesity (a recent meta-analysis by $\mathrm{Gu}$ et al., 2020), or a positive association between $\mathrm{Cu}$ level in serum or adipose tissue and BMI [72,73], which, altogether, suggest that $\mathrm{Cu}$ status is strongly related to BMI, independently of pregnancy. Interestingly, Yang et al. (2019) have found that total $\mathrm{Cu}$ levels positively correlate with leptin, insulin, and leptin/BMI suggesting that $\mathrm{Cu}$ and/or cuproproteins may be functionally linked to fat accumulation [73]. Nevertheless, the role of $\mathrm{Cu}$ in obesity has not been elucidated yet and, thus, it is not possible to conclude about adequacy of $\mathrm{Cu}$ status in overweight pregnant women and make any special dietary recommendations concerning $\mathrm{Cu}$ intake in this group. 
The vitamin E mean concentration noted in our population $(8.2 \mathrm{mg} / \mathrm{L} \pm 3.6 \mathrm{mg} / \mathrm{L})$ is similar to that reported by Chen et al. (2018) $(9.1 \mathrm{mg} / \mathrm{L} \pm 2.5 \mathrm{mg} / \mathrm{L})$ [74]. Higher vitamin concentration among older women seems to be rather related to their dietary choices not to supplementation.

The prospective study design with a reliable assessment of several lifestyle or pregnancyrelated factors (i.e., a cotinine level in saliva as a biomarker of smoking status, pregnancy complications, or supplement use evaluated by a gynecologist or midwife during a detailed interview) is an important strength of the current study. Additionally, our assessments were based on a medium-to-large sample size population. It also needs to be pointed out that the study was restricted to the healthy women, in healthy pregnancy not assisted with reproduction technologies, which, in principle, means that the women did not require special diets or medical treatment. Moreover, we evaluated a set of essential elements and vitamins intake based on the questionnaire data and also for some minerals and vitamins based on their concentration measured in blood. Consumption of supplements was also taken into account. Finally, we looked at a variety of determinants (socio-demographic, lifestyle-related, environmental, and pregnancy-related factors) of an adequate essential elements and vitamin status during pregnancy, which can provide more accurate information for the development of dietary interventions targeting vulnerable groups. Limitations of the study are related to the assessment of dependent variables, which was mostly based on FFQ data (for six minerals and nine vitamins) and only for a few nutrients also based on laboratory assessments (for three minerals and two vitamins). Thus, over or underreporting of nutrients intake could occur. Moreover, declared food intake may also not correspond to the nutritional status measured by laboratory means as a result of different bioavailability of nutrients from different food products and individual differences in metabolism. Even though questionnaire data is typical of public health research, both measures are needed for appropriate assessment of a nutritional status and to support the conclusions drawn within this study $[51,65,75]$. To minimize the measurement error when assessing dietary intake with $F F Q$, future studies should be eventually validated using duplicate portions technique [76]. The study by Thijsburg et al. indicated that duplicate portions technique was less influenced by proportional scaling bias, and correlated errors between duplicate portions technique and FFQ were lowest compared with the $24 \mathrm{HR}$. Attenuation factors also indicated that the duplicate portions technique performed better than the 24HR. Therefore, the authors conclude that the duplicate portions technique is probably the best available reference method for FFQ validation for nutrients that currently have no generally accepted biomarker. We did not collect data at several time points, simultaneously making it impossible to identify any changes in dietary patterns throughout the pregnancy period. Moreover, even though we have evaluated a wide range of potential determinants of nutritional status, some food policies and recommendations or weight concern, which all can impact the women's decisions regarding dietary choices were omitted. Finally, the data presented in this manuscript are from the phase of the study that was performed between 2007 and 2011 so the pattern of a diet and supplement use might have changed over the time. In this respect, more updated data are needed-ideally presenting the results from validated questionnaires as well as biological sample assessments.

\section{Conclusions}

Diet of pregnant women, despite existing recommendations, is still significantly lacking balance for specific minerals and vitamins crucial for the proper development of a fetus and children's health. Further efforts to encourage women to establish healthy dietary practices before conception and throughout the pregnancy period are warranted. The less educated women, and those with coexisting less favorable lifestyles should be target groups for such actions. Promotion of the 1st medicalcare visit as early during pregnancy as possible also creates a possibility to monitor nutritional status of the women early and introduce promotional and educational interventions. Finally, more studies are required, especially based on laboratory measures, to provide a more reliable assessment 
of nutritional status during pregnancy and to implement adequate preventive measures. The duplicate portions technique can be considered as the best available reference method for FFQ validation in the case that laboratory measurements are not possible.

Supplementary Materials: The following are available online at https:/ / www.mdpi.com/2072-664 3/13/3/949/s1, Table S1: Estimated average requirement (EAR) for selected essential elements and vitamins during pregnancy, Table S2: Characteristics of the study population $(\mathrm{N}=1252)$, Table S3: Percentage of pregnant women using dietary supplementation and percentages of selected essential elements and vitamins from the supplements $(n=1233)$, Table S4: Average daily intake of essential elements and vitamins with diet and in total (diet and supplements) $(n=1252)$, Table S5: Univariable models for the adequacy of intake of selected essential elements and vitamins from dietary sources $(n=1011)$, Table S6: Univariable models for the adequacy of intake of selected essential elements and vitamins from total: dietary and supplements sources $(n=1005)$, Table S7: Multivariable models for the adequacy of intake of selected essential elements and vitamins from dietary sources $(n=1011)$, Table S8: Multivariable models for the adequacy of intake of selected essential elements and vitamins from total: dietary and supplements $(n=1005)$, Table S9: Microelements and vitamins concentrations in plasma collected during the 1st trimester of pregnancy (microelements: $n=340$; vitamins: $n=358$ ), Table S10. Coefficients of univariable linear regression model of microelements and vitamins concentration in plasma collected during the 1st trimester of pregnancy depending on selected factors (microelements: $n=340$; vitamins: $n=358$ ).

Author Contributions: A.J., E.W. and M.K. (Michał Krekora) performed the literature search, participated in the interpretation of the results, and co-drafted the paper; E.T. was involved in the assessment of maternal essential elements and vitamins intake with diet, participated in the interpretation of the results and co-drafted the paper; B.J., J.G., and W.W. performed assessment and interpretation of microelements concentration in biological samples; P.K. performed the statistical analysis and co-drafted the paper; J.D., M.G. and M.K. (Michał Krekora) performed fieldwork and literature search; W.H., I.S.-S., M.K. (Małgorzata Kowalska), D.K., J.J., W.W., B.J., J.G., E.J. and G.C. contributed intellectually to the development of the final manuscript, K.P. developed the original idea for the analysis and intellectually contributed to the development of the final manuscript. All authors have read and agreed to the published version of the manuscript.

Funding: This work has been funded by the National Science Centre under the call JPI HDHL Nutrition and Cognitive Function (2015/17/Z/NZ7/04273), the National Centre for Re-search and Development (ERA-HDHL/01/ALPHABET/1/2017), and internal grants IMP9.9/2020 and IMP10.34/2020.

Institutional Review Board Statement: The study was conducted according to the guidelines of the Declaration of Helsinki, and approved by the Ethical Committee of the Nofer Institute of Occupational Medicine, Lodz, Poland (Decision No. 7/2007 on 5 March 2007).

Informed Consent Statement: Informed consent was obtained from all subjects involved in the study.

Data Availability Statement: The data presented in this study are available on request from the corresponding author. The data are not publicly available due to privacy and ethical restrictions.

Conflicts of Interest: The authors declare no conflict of interest.

\section{References}

1. Fall, C. Maternal nutrition: Effects on health in the next generation. Indian J. Med. Res. 2009, 130, 593-599. [PubMed]

2. King, J.C. Maternal obesity, metabolism, and pregnancy outcomes. Annu. Rev. Nutr. 2006, 26, 271-291. [CrossRef] [PubMed]

3. Plows, F.J.; Stanley, L.J.; Baker, N.P.; Reynolds, M.C.; Vickers, H.M. The Pathophysiology of Gestational 491 Diabetes Mellitus. Int. J. Mol. Sci. 2018, 19, 3342. [CrossRef] [PubMed]

4. World Health Organization (WHO). WHO Recommendations on Antenatal Care for a Positive Pregnancy Experience. Available online: https: / /www.who.int/publications/i/item/9789241549912 (accessed on 20 December 2020).

5. World Health Organization (WHO). WHO Antenatal Care Recommendations for a Positive Pregnancy Experience Nutritional Interventions Update: Multiple Micronutrient Supplements during Pregnancy. Available online: https:/ /www.who.int/ publications/i/item/9789240007789 (accessed on 20 January 2021).

6. Heindel, J.J.; Balbus, J.; Birnbaum, L.; Brune-Drisse, M.N.; Grandjean, P.; Gray, K.; Landrigan, P.J.; Sly, P.D.; Suk, W.; Cory Slechta, D.; et al. Developmental Origins of Health and Disease: Integrating Environmental Influences. Endocrinology 2015, 156, $3416-3421$. [CrossRef] [PubMed] 
7. Leermakers, E.T.M.; Tielemans, M.J.; van den Broek, M.; Jaddoe, V.W.V.; Franco, O.H.; Kiefte-de Jong, J.C. Maternal dietary patterns during pregnancy and offspring cardiometabolic health at age 6 years: The generation R study. Clin. Nutr. 2017, 36, 477-484. [CrossRef] [PubMed]

8. Chatzi, L.; Rifas-Shiman, S.L.; Georgiou, V.; Joung, K.E.; Koinaki, S.; Chalkiadaki, G.; Margioris, A.; Sarri, K.; Vassilaki, M.; Vafeiadi, M.; et al. Adherence to the Mediterranean diet during pregnancy and offspring adiposity and cardiometabolic traits in childhood. Pediatr. Obes. 2017, 12 (Suppl. 1), 47-56. [CrossRef] [PubMed]

9. Chen, X.; Zhao, D.; Mao, X.; Xia, Y.; Baker, P.N.; Zhang, H. Maternal Dietary Patterns and Pregnancy Outcome. Nutrients 2016, 8, 351. [CrossRef]

10. Chen, L.W.; Aris, I.M.; Bernard, J.Y.; Tint, M.T.; Chia, A.; Colega, M.; Gluckman, P.D.; Shek, L.P.; Saw, S.M.; Chong, Y.S.; et al. Associations of Maternal Dietary Patterns during Pregnancy with Offspring Adiposity from Birth Until 54 Months of Age. Nutrients 2016, 9, 2. [CrossRef]

11. Beckhaus, A.A.; Garcia-Marcos, L.; Forno, E.; Pacheco-Gonzalez, R.M.; Celedón, J.C.; Castro-Rodriguez, J.A. Maternal nutrition during pregnancy and risk of asthma; wheeze; and atopic diseases during childhood: A systematic review and meta-analysis. Allergy 2015, 70, 1588-1604. [CrossRef]

12. Borge, T.C.; Aase, H.; Brantsæter, A.L.; Biele, G. The importance of maternal diet quality during pregnancy on cognitive and behavioural outcomes in children: A systematic review and meta-analysis. BMJ Open 2017, 24, e016777. [CrossRef]

13. Barker, D.J. Fetal origins of coronary heart disease. BMJ 1995, 15, 171-174. [CrossRef] [PubMed]

14. Barker, D.J. The origins of the developmental origins theory. J. Intern. Med. 2007, 261, 4127. [CrossRef]

15. World Health Organization (WHO). WHO Antenatal Care Recommendations for a Positive Pregnancy Experience Nutritional Interventions Update: Vitamin D Supplements during Pregnancy. Available online: https://apps.who.int/iris/handle/10665/33 3562 (accessed on 20 January 2021).

16. Zimmer, M.; Sieroszewski, P.; Oszukowski, P.; Huras, H.; Fuchs, T.; Pawlosek, A. Polish Society of Gynecologists and Obstetricians recommendations on supplementation during pregnancy. Ginekol. Pol. 2020, 91, 644-653. [CrossRef] [PubMed]

17. Blumfield, M.L.; Hure, A.J.; Macdonald-Wicks, L.; Smith, R.; Collins, C.E. A systematic review and meta-analysis of micronutrient intakes during pregnancy in developed countries. Nutr. Rev. 2013, 71, 118-132. [CrossRef] [PubMed]

18. Gardner, B.; Croker, H.; Barr, S.; Briley, A.; Poston, L.; Wardle, J.; on behalf of the UPBEAT Trial. Psychological predictors of dietary intentions in pregnancy. J. Hum. Nutr. Diet. 2012, 25, 345-353. [CrossRef]

19. Doyle, I.M.; Borrmann, B.; Grosser, A.; Razum, O.; Spallek, J. Determinants of dietary patterns and diet quality during pregnancy: A systematic review with narrative synthesis. Public Health Nutr. 2017, 20, 1009-1028. [CrossRef] [PubMed]

20. Polańska, K.; Hanke, W.; Gromadzińska, J.; Ligocka, D.; Gulczyńska, E.; Sobala, W.; Wassowicz, W. Polish mother and child cohort study-defining the problem; the aim of the study and methodological assumption. Int. J. Occup. Med. Environ. Health 2009, 22, 383-391. [CrossRef]

21. Polańska, K.; Hanke, W.; Jurewicz, J.; Sobala, W.; Madsen, C.; Nafstad, P.; Magnus, P. Polish mother and child cohort study (REPRO_PL)-methodology of follow-up of the children. Int. J. Occup. Med. Environ. Health 2011, 24, 391-398. [CrossRef]

22. Polańska, K.; Hanke, W.; Król, A.; Potocka, A.; Waszkowska, M.; Jacukowicz, A.; Gromadzińska, J.; Wąsowicz, W.; Jerzyńska, J.; Stelmach, W.; et al. Polish Mother and Child Cohort Study (REPRO_PL)-Methodology of the follow-up of the children at the age of 7. Int. J. Occup. Med. Environ. Health 2016, 29, 883-893. [CrossRef]

23. Tobias, D.K.; Hu, F.B.; Chavarro, J.; Rosner, B.; Mozaffarian, D.; Zhang, C. Healthful dietary patterns and type 2 diabetes mellitus risk among women with a history of gestational diabetes mellitus. Arch. Intern. Med. 2012, 12, 1566-1572. [CrossRef]

24. Qiu, C.; Zhang, C.; Gelaye, B.; Enquobahrie, D.A.; Frederick, I.O.; Williams, M.A. Gestational diabetes mellitus in relation to maternal dietary heme iron and nonheme iron intake. Diabetes Care 2011, 34, 1564-1569. [CrossRef]

25. Rimm, E.B.; Giovannucci, E.L.; Stampfer, M.J.; Colditz, G.A.; Litin, L.B.; Willett, W.C. Reproducibility and validity of an expanded self-administered semiquantitative food frequency questionnaire among male health professionals. Am. J. Epidemiol. 1992, 135, 1114-1126. [CrossRef] [PubMed]

26. Klipstein-Grobusch, K.; den Breeijen, J.H.; Goldbohm, R.A.; Geleijnse, J.M.; Hofman, A.; Grobbee, D.E.; Witteman, J.C. Dietary assessment in the elderly: Validation of a semiquantitative food frequency questionnaire. Eur. J. Clin. Nutr. 1998, 52, 588-596. [CrossRef]

27. Wesołowska, E.; Jankowska, A.; Trafalska, E.; Kałużny, P.; Grzesiak, M.; Dominowska, J.; Hanke, W.; Calamandrei, G.; Polańska, K. Sociodemographic, Lifestyle, Environmental and Pregnancy-Related Determinants of Dietary Patterns during Pregnancy. Int. J. Environ. Res. Public Health 2019, 16, 754. [CrossRef] [PubMed]

28. Aubert, A.M.; Forhan, A.; de Lauzon-Guillain, B.; Chen, L.W.; Polanska, K.; Hanke, W.; Jankowska, A.; Mensink-Bout, S.M.; Duijts, L.; Suderman, M.; et al. Deriving the Dietary Approaches to Stop Hypertension (DASH) Score in Women from Seven Pregnancy Cohorts from the European ALPHABET Consortium. Nutrients 2019, 11, 2706. [CrossRef]

29. Kunachowicz, H.; Przygoda, B.; Nadolna, I.; Iwanow, K. Tabele Składu i Wartości Odżywczej Żywności; Publisher PZWL: Warsaw, Poland, 2017.

30. Jarosz, M. Nutrition Standards for Polish Population; National Food and Nutrition Institute: Warsaw, Poland, 2017; Available online: https:/ / ncez.pl (accessed on 20 December 2020). 
31. Polanska, K.; Hanke, W.; Krol, A.; Gromadzinska, J.; Kuras, R.; Janasik, B.; Wasowicz, W.; Mirabella, F.; Chiarotti, F.; Calamandrei, G. Micronutrients during pregnancy and child psychomotor development: Opposite effects of Zinc and Selenium. Environ. Res. 2017, 158, 583-589. [CrossRef]

32. Gromadzinska, J.; Polanska, K.; Kozlowska, L.; Mikolajewska, K.; Stelmach, I.; Jerzyńska, J.; Stelmach, W.; Grzesiak, M.; Hanke, W.; Wasowicz, W. Vitamins A and E during Pregnancy and Allergy Symptoms in an Early Childhood-Lack of Association with Tobacco Smoke Exposure. Int. J. Environ. Res. Public Health 2018, 15, 1245. [CrossRef]

33. Agarwal, R.P.; Henkon, R.L. A simple method for simultaneous estimation of zinc and copper in erythrocytes. Biol. Trace. Elem. Res. 1985, 7, 199-208. [CrossRef] [PubMed]

34. Neve, J.; Molle, L. Direct determination of selenium in human serum by graphite furnace atomic absorption spectroscopy Improvements due to oxygen ashing in graphite tube and Zeeman effect background correction. Acta Pharmacol. Toxicol. 1986, 59, 606-609. [CrossRef] [PubMed]

35. Neve, J.; Chamart, S.; Molle, L. Optimization of direct procedure for the determination of selenium in plasma and erythrocytes using Zeeman effect atomic absorption spectroscopy. Trace Elem. Anal. Chem. Med. Biol. 1987, 4, 349-358.

36. Grzelinska, Z.; Gromadzinska, J.; Swiercz, R.; Wasowicz, W. Plasma concentration of vitamin E, vitamin Aand b-carotene in healthy men. Pol. J. Environ. Study 2007, 16, 209-213.

37. Stragierowicz, J.; Mikołajewska, K.; Zawadzka-Stolarz, M.; Polanska, K.; Ligocka, D. Estimation of cutoff values of cotinine in urine and saliva for pregnant women in Poland. Biomed. Res. Int. 2013, 2013, 386784.

38. R Core Team 2018. R: A Language and Environment for Statistical Computing; R Foundation for Statistical Computing: Vienna, Austria, 2018; Available online: https: / www.R-project.org/ (accessed on 20 January 2021).

39. World Health Organization (WHO). Healthy Diet. Fact Sheet No. 394. Geneva, Updated 30 August 2018. Available online: https://www.who.int/publications/m/item/healthy-diet-factsheet394 (accessed on 21 January 2021).

40. Oliver, E.M.; Grimshaw, K.E.; Schoemaker, A.A.; Keil, T.; McBride, D.; Sprikkelman, A.B.; Ragnarsdottir, H.S.; Trendelenburg, V.; Emmanouil, E.; Reche, M.; et al. Dietary habits and supplement use in relation to national pregnancy recommendations: Data from the EuroPrevall birth cohort. Matern. Child Health J. 2014, 18, 2408-2425. [CrossRef] [PubMed]

41. Bailey, R.L.; Pac, S.G.; Fulgoni, V.L., 3rd; Reidy, K.C.; Catalano, P.M. Estimation of Total Usual Dietary Intakes of Pregnant Women in the United States. JAMA Netw. Open. 2019, 2, e195967. [CrossRef]

42. Brown, B.; Wright, C. Safety and efficacy of supplements in pregnancy. Nutr. Rev. 2020, 78, 813-826. [CrossRef]

43. Knapik, A.; Kocot, K.; Witek, A.; Jankowski, M.; Wróblewska-Czech, A.; Kowalska, M.; Zejda, J.E.; Brożek, G. Dietary supplementation usage by pregnant women in Silesia-Population based study. Ginekol. Pol. 2018, 89, 506-512. [CrossRef]

44. Arkkola, T.; Uusitalo, U.; Pietikainen, M.; Metsala, J.; Kronberg-Kippila, C.; Erkkola, M.; Ovaskainen, M.L. Dietary intake and use of dietary supplements in relation to demographic variables among pregnant Finnish women. Br. J. Nutr. 2006, 96, 913-920. [CrossRef]

45. Kocyłowski, R.; Lewicka, I.; Grzesiak, M.; Gaj, Z.; Sobańska, A.; Poznaniak, J.; von Kaisenberg, C.; Suliburska, J. Assessment of dietary intake and mineral status in pregnant women. Arch. Gynecol. Obstet. 2018, 297, 1433-1440. [CrossRef]

46. Bojar, I.; Owoc, A.; Humeniuk, E.; Wierzba, W.; Fronczak, A. Inappropriate consumption of vitamins and minerals by pregnant women in Poland. Ann. Agric. Environ. Med. 2012, 19, 263-266.

47. Institute of Mother and Child. Dietary Recommendations for Pregnant Women. Available online: https://imid.med.pl/images/ poradnik-zywienia-dla-kobiet-w-ciazy.pdf (accessed on 21 January 2021).

48. Food and Nutrition Institute. Available online: https:/ /ncez.pl/ciaza-i-macierzynstwo/plodnosc-i-ciaza (accessed on 21 January 2021).

49. Georgieff, M.K.; Krebs, N.F.; Cusick, S.E. The Benefits and Risks of Iron Supplementation in Pregnancy and Childhood. Annu Rev Nutr. 2019, 39, 121-146. [CrossRef]

50. Park, K.; Rimm, E.; Siscovick, D.; Spiegelman, D.; Morris, J.S.; Mozaffarian, D. Demographic and lifestyle factors and selenium levels in men and women in the U.S. Nutr. Res. Pract. 2011, 5, 357-364. [CrossRef] [PubMed]

51. Livock, M.; Anderson, P.J.; Lewis, S.; Bowden, S.; Muggli, E.; Halliday, J. Maternal micronutrient consumption periconceptionally and during pregnancy: A prospective cohort study. Public Health Nutr. 2017, 20, 294-304. [CrossRef] [PubMed]

52. Barden, A.; Zilkens, R.R.; Croft, K.; Mori, T.; Burke, V.; Beilin, L.J.; Puddey, I.B. A reduction in alcohol consumption is associated with reduced plasma F2-isoprostanes and urinary 20-HETE excretion in men. Free Radic. Biol. Med. 2007, 42, 1730-1735. [CrossRef] [PubMed]

53. De Santis, M.; Quattrocchi, T.; Mappa, I.; Spagnuolo, T.; Licameli, A.; Chiaradia, G.; De Luca, C. Folic acid use in planned pregnancy: An Italian survey. Matern. Child Health J. 2013, 17, 661-666. [CrossRef]

54. Nasr Hage, C.; Jalloul, M.; Sabbah, M.; Adib, S.M. Awareness and intake of folic acid for the prevention of neural tube defects among Lebanese women of childbearing age. Matern. Child Health J. 2012, 16, 258-265. [CrossRef]

55. Roth, C.; Bjørke-Monsen, A.L.; Reichborn-Kjennerud, T.; Nilsen, R.M.; Smith, G.D.; Stoltenberg, C.; Surén, P.; Susser, E.; Ueland, P.M.; Vollset, S.E.; et al. Use of folic acid supplements in early pregnancy in relation to maternal plasma levels in week 18 of pregnancy. Mol. Nutr. Food Res. 2013, 57, 653-660. [CrossRef]

56. McNally, S.; Bourke, A. Periconceptional folic acid supplementation in a nationally representative sample of mothers. Ir. Med. J. 2012, 105, 236-238.

57. Forster, D.A.; Wills, G.; Denning, A.; Bolger, M. The use of folic acid and other vitamins before and during pregnancy in a group of women in Melbourne, Australia. Midwifery 2009, 25, 134-146. [CrossRef] 
58. Pouchieu, C.; Lévy, R.; Faure, C.; Andreeva, V.A.; Galan, P.; Hercberg, S.; Touvier, M. Socioeconomic, lifestyle and dietary factors associated with dietary supplement use during pregnancy. PLoS ONE 2013, 13, e70733. [CrossRef]

59. Choi, R.; Sun, J.; Yoo, H.; Kim, S.; Cho, Y.Y.; Kim, H.J.; Kim, S.W.; Chung, J.H.; Oh, S.-Y.; Lee, S.-Y. A Prospective Study of Serum Trace Elements in Healthy Korean Pregnant Women. Nutrients 2016, 8, 749. [CrossRef]

60. Liang, C.M.; Wu, X.Y.; Huang, K.; Yan, S.Q.; Li, Z.J.; Xia, X.; Pan, W.J.; Sheng, J.; Tao, Y.R.; Xiang, H.Y.; et al. Trace element profiles in pregnant women's sera and umbilical cord sera and influencing factors: Repeated measurements. Chemosphere 2019, 218, 869-878. [CrossRef] [PubMed]

61. Vitale, K.; Mujkić, A.; Todorović, G.; Tulchinsky, T. Is level of knowledge, attitude and use of folic acid among pregnant women in Croatia a call for public health action? Period. Biol. 2009, 111, 329-335.

62. Northstone, K.; Emmett, P.; Rogers, I. Dietary patterns in pregnancy and associations with socio-demographic and lifestyle factors. Eur. J. Clin. Nutr. 2008, 62, 471-479. [CrossRef] [PubMed]

63. Arkkola, T.; Uusitalo, U.; Kronberg-Kippilä, C.; Männistö, S.; Virtanen, M.; Kenward, M.G.; Veijola, R.; Knip, M.; Ovaskainen, M.L.; Virtanen, S.M. Seven distinct dietary patterns identified among pregnant Finnish women-Associations with nutrient intake and sociodemographic factors. Public Health Nutr. 2008, 11, 176-182. [CrossRef]

64. Völgyi, E.; Carroll, K.N.; Hare, M.E.; Ringwald-Smith, K.; Piyathilake, C.; Yoo, W.; Tylavsky, F.A. Dietary patterns in pregnancy and effects on nutrient intake in the Mid-South: The Conditions Affecting Neurocognitive Development and Learning in Early Childhood (CANDLE) study. Nutrients 2013, 5, 1511-1530. [CrossRef] [PubMed]

65. de Castro, M.B.; Freitas Vilela, A.A.; de Oliveira, A.S.; Cabral, M.; de Souza, R.A.; Kac, G.; Sichieri, R. Sociodemographic characteristics determine dietary pattern adherence during pregnancy. Public Health Nutr. 2016, 19, 1245-1251. [CrossRef]

66. Polanska, K.; Krol, A.; Sobala, W.; Gromadzinska, J.; Brodzka, R.; Calamandrei, G.; Chiarotti, F.; Wasowicz, W.; Hanke, W. Selenium status during pregnancy and child psychomotor development-Polish Mother and Child Cohort study. Pediatr. Res. 2016, 79, 863-869. [CrossRef]

67. Mensink, G.B.; Fletcher, R.; Gurinovic, M.; Huybrechts, I.; Lafay, L.; Serra-Majem, L.; Szponar, L.; Tetens, I.; Verkaik-Kloosterman, J.; Baka, A.; et al. Mapping low intake of micronutrients across Europe. Br. J. Nutr. 2013, 110, 755-773. [CrossRef]

68. Cetin, I.; Berti, C.; Calabrese, S. Role of micronutrients in the periconceptional period. Hum. Reprod. Update 2010, 16, 80-95. [CrossRef]

69. Yang, X.; Yu, X.; Fu, H.; Li, L.; Ren, T. Different levels of prenatal zinc and selenium had different effects on neonatal neurobehavioral development. Neurotoxicology 2013, 37, 35-39. [CrossRef]

70. Rayman, M.P. Selenium and human health. Lancet 2012, 379, 1256-1268. [CrossRef]

71. Pathak, P.; Kapil, U.; Kapoor, S.K.; Saxena, R.; Kumar, A.; Gupta, N.; Dwivedi, S.N.; Singh, R.; Singh, P. Prevalence of multiple micronutrient deficiencies amongst pregnant women in a rural area of Haryana. Indian J. Pediatr. 2004, 71, 1007-1014. [CrossRef] [PubMed]

72. Gu, K.; Li, X.; Xiang, W.; Jiang, X. The Relationship between Serum Copper and Overweight/Obesity: A Meta-analysis. Biol. Trace Elem. Res. 2020, 194, 336-347. [CrossRef] [PubMed]

73. Yang, H.; Liu, C.N.; Wolf, R.M.; Ralle, M.; Dev, S.; Pierson, H.; Askin, F.; Steele, K.E.; Magnuson, T.H.; Schweitzer, M.A.; et al. Obesity is associated with copper elevation in serum and tissues. Metallomics 2019, 11, 1363-1371. [CrossRef]

74. Chen, H.; Qian, N.; Yan, L.; Jiang, H. Role of serum vitamin A and E in pregnancy. Exp. Ther. Med. 2018, 16, 5185-5189. [CrossRef]

75. Ramage, S.M.; McCargar, L.J.; Berglund, C.; Harber, V.; Bell, R.C.; APrON Study Team. Assessment of Pre-Pregnancy Dietary Intake with a Food Frequency Questionnaire in Alberta Women. Nutrients 2015, 7, 6155-6166. [CrossRef]

76. Trijsburg, L.; de Vries, J.H.; Boshuizen, H.C.; Hulshof, P.J.; Hollman, P.C.; van't Veer, P.; Geelen, A. Comparison of duplicate portion and $24 \mathrm{~h}$ recall as reference methods for validating a FFQ using urinary markers as the estimate of true intake. Br. J. Nutr. 2015, 114, 1304-1312. [CrossRef] 